\title{
Egg consumption and the risk of type 2 diabetes mellitus: a case-control study
}

\author{
Lina Radzevičienè * and Rytas Ostrauskas \\ Institute of Endocrinology, Medical Academy, Lithuanian University of Health Sciences, Eiveniu 2, \\ 50009 Kaunas, Lithuania
}

Submitted 6 July 2011: Accepted 20 January 2012: First published online 6 March 2012

\begin{abstract}
Objective: Type 2 diabetes mellitus appears to involve an interaction between susceptible genetic backgrounds and environmental factors including highly calorific diets. As it is important to identify modifiable risk factors that may help reduce the risk of type 2 diabetes mellitus, the aim of the present study was to determine the association between egg consumption and the risk of type 2 diabetes mellitus.

Design: A specifically designed questionnaire was used to collect information on possible risk factors of type 2 diabetes mellitus. The odds ratios and $95 \%$ confidence intervals for type 2 diabetes mellitus were calculated by conditional logistic regression.

Setting: A case-control study in a Lithuanian out-patient clinic was performed in 2001.

Subjects: A total of 234 cases with a newly confirmed diagnosis of type 2 diabetes mellitus and 468 controls free of the disease.

Results: Variables such as BMI, family history of diabetes, cigarette smoking, education, morning exercise and plasma TAG level were retained in multivariate logistic regression models as confounders because their inclusion changed the value of the odds ratio by more than $10 \%$ in any exposure category. After adjustment for possible confounders more than twofold increased risk of type 2 diabetes mellitus was determined for individuals consuming 3-4.9 eggs/week $(\mathrm{OR}=2 \cdot 60 ; 95 \% \mathrm{CI} 1 \cdot 34,5 \cdot 08)$ and threefold increased risk of the disease was determined for individuals consuming $\geq 5$ eggs/week $(\mathrm{OR}=3 \cdot 02$; 95\% CI 1.14, 7.98) compared with those eating $<1$ egg/week.

Conclusions: Our data support a possible relationship of egg consumption and increased risk of type 2 diabetes mellitus.
\end{abstract}

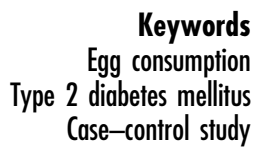

Type 2 diabetes mellitus is increasing in prevalence globally $^{(1)}$ and is becoming a world pandemic. The total number of people with diabetes is projected to rise from 171 million in 2000 to 366 million in $2030^{(2)}$. The number of people with diabetes is increasing due to population growth, ageing, urbanization and the increasing prevalences of obesity and physical inactivity ${ }^{(2)}$. The prevalence of type 2 diabetes mellitus is $4.5 \%$ among people aged 35-65 years in Lithuania ${ }^{(3)}$.

Type 2 diabetes appears to involve an interaction between susceptible genetic backgrounds and environmental factors including highly calorific diets ${ }^{(4)}$. Eggs are a major source of dietary cholesterol, with an average egg containing about $200 \mathrm{mg}$ of cholesterol. On the other hand, eggs contain other nutrients such as minerals, folate, B vitamins, fat-soluble vitamins A, D, E and $\mathrm{K}$, carotenoids and saturated, monounsaturated and polyunsaturated fatty acids ${ }^{(5-7)}$.
In the last decade, usage of eggs increased in Lithuania (from 176 to 191 eggs per capita) ${ }^{(8)}$. In food ration eggs are often used, because poultry farming is highly developed and eggs are one of the cheapest food types in Lithuania.

As consumption of eggs is related to the development of some chronic non-infectious diseases ${ }^{(9)}$, we decided to investigate if an increase in incidence of type 2 diabetes mellitus could partly be related to habits of egg consumption. Thus we performed a case-control study in an out-patient clinic in Kaunas, Lithuania, with the aim to determine the relationship between egg consumption and risk of type 2 diabetes mellitus.

\section{Materials and methods}

A case-control study was carried out at an out-patient clinic in Kaunas, Lithuania, in 2001. The study included 234 cases 
aged 35-86 years with a newly confirmed diagnosis of type 2 diabetes mellitus according to $\mathrm{WHO}$ criteria $^{(10)}$. In total, 468 controls who had neither impaired fasting glucose level nor type 2 diabetes mellitus after a glucose tolerance test were recruited from patients of the same clinic. They were individually matched to the diabetic patients by gender and age ( \pm 5 years). The ratio of cases to controls was 1:2.

Information on age, gender, family history of diabetes, education, occupational and marital status, egg consumption, alcohol consumption, cigarette smoking, physical activity and stress level was assessed by a special questionnaire designed by our research group. All study participants were asked to fill out the questionnaire by themselves.

Participants were asked to fast for $12 \mathrm{~h}$ and to avoid smoking and heavy physical activity for at least $2 \mathrm{~h}$ before the examinations. After a $5 \mathrm{~min}$ rest in a quiet room, systolic and diastolic blood pressure levels were measured twice at an interval of a few minutes on the right arm with a standard mercury sphygmomanometer with $2 \cdot 0 \mathrm{mmHg}$ column accuracy. Anthropometric measurements were made according to the guidelines of $\mathrm{WHO}^{(11)}$. Height and weight were measured twice. Height was measured without shoes in centimetres $(0 \cdot 1 \mathrm{~cm}$ accuracy). Weight was measured with light clothing in kilograms $\left(0.5 \mathrm{~kg}\right.$ accuracy). BMI $\left(\mathrm{kg} / \mathrm{m}^{2}\right)$ was calculated as weight (in kilograms) divided by the square of height (in metres) ${ }^{(12)}$. Waist circumference was measured by holding a non-stretchable measuring tape snugly around the waist, defined as the midpoint between the bottom rib and the tip of the hipbones, and hip circumference was measured at the level of the great femur trochanters; both were measured in centimetres $(0 \cdot 1 \mathrm{~cm}$ accuracy).

Laboratory blood tests included fasting blood samples drawn from participants' elbow vein and venous plasma samples analysed for glucose and TAG levels. Plasma glucose was estimated by the GOD-PAP method (EBIO compact analyser; Eppendorf, Germany). Plasma TAG was estimated by the GPO-PAP method (RA-50 clinical chemistry analyser; Bayer Diagnostics, Ireland). According to the recommendations of $\mathrm{WHO}^{(10)}$, a $75 \mathrm{~g}$ oral glucose tolerance test for assessing carbohydrate disorders was performed and evaluated in each study participant.

Study variables were categorized as follows.

1. Egg consumption: $<1$ egg/week, 1-1.9 eggs/week, 2-2.9 eggs/week, 3-4.9 eggs/week and $\geq 5$ eggs/week.

2. BMI: $18 \cdot 5-24 \cdot 9 \mathrm{~kg} / \mathrm{m}^{2}, 25 \cdot 0-29 \cdot 9 \mathrm{~kg} / \mathrm{m}^{2}$ and $\geq 30 \cdot 0 \mathrm{~kg} / \mathrm{m}^{2}$.

3. Family history of diabetes: first-degree relatives with diabetes and first-degree relatives without diabetes.

4. Cigarette smoking: non-smoker, ex-smoker, infrequent smoker and current smoker.

5. Level of education (number of years): $\leq 10$ years, 11-13 years and $\geq 14$ years.

6. Morning exercise (of at least $30 \mathrm{~min}$ duration) during the last 12 months: no, sometimes and yes.

7. Plasma TAG: $<1.7 \mathrm{mmol} / 1$ and $\geq 1.7 \mathrm{mmol} / 1$.
Conditional logistic regression was used to calculate odds ratios and corresponding 95\% confidence intervals for diabetes mellitus in relation to exposures of interest. Variables such as BMI, family history of diabetes, cigarette smoking, education, morning exercise and plasma TAG level were retained in models as confounders when their inclusion changed the value of the odds ratio by more than $10 \%$ in any exposure category.

All reported trend test significance levels ( $P$ values) were two-sided ${ }^{(13)}$. The $\chi^{2}$ test was utilized to calculate the difference between proportions. The level of significance was set at 5\%. All calculations were performed with the STATA statistical software package version 7 (StataCorp., College Station, TX, USA).

\section{Results}

The characteristics of the case (type 2 diabetic patients) and control groups are displayed in Table 1 . In our study there were $28.21 \%$ men and $71.79 \%$ women. The mean age was 64.09 (SD 7.85) years (range: 39-86 years) for men and 65.23 (sD 8.3) years (range: 34-86 years) for women. The cases had significantly lower education level compared with the controls. Their BMI was higher than in the controls'. There were more controls without a family history of diabetes (first-degree relatives without diabetes) than cases.

Univariate regression modelling showed that participants who consumed $\geq 5$ eggs/week had a higher risk of type 2 diabetes mellitus (crude OR $=1 \cdot 27 ; 95 \%$ CI 1·10, 1·46) than those who consumed $<1$ egg/week. A dose-response relationship was defined between risk of this disease and egg consumption ( $P$ for trend $=0 \cdot 001$ ).

Variables such as BMI, family history of diabetes, cigarette smoking, education, morning exercise and plasma TAG level were retained in multivariate logistic regression models as confounders because their inclusion changed the value of the odds ratio by more than $10 \%$ in any exposure category. Multivariate logistic regression data showing the relationship between type 2 diabetes mellitus and egg consumption are presented in Table 2. After adjusting for BMI, family history of diabetes, smoking and education, it was found that the excess risk of type 2 diabetes mellitus because of egg consumption changed a little, but remained statistically significant. After further controlling for BMI, family history of diabetes, smoking, education, morning exercise and plasma TAG level, we found a threefold increased risk of type 2 diabetes mellitus in participants who consumed $\geq 5$ eggs/week $(\mathrm{OR}=3 \cdot 02 ; 95 \%$ CI $1 \cdot 14,7 \cdot 98)$ compared with those eating $<1 \mathrm{egg} /$ week.

\section{Discussion}

The present study has demonstrated an increased risk of type 2 diabetes mellitus related to egg consumption. 
Egg consumption and type 2 diabetes

Table 1 Characteristics of the study participants: cases ( $n$ 234) with a newly confirmed diagnosis of type 2 diabetes mellitus and age/gender-matched controls ( $n$ 468), Kaunas, Lithuania, 2001

\begin{tabular}{|c|c|c|c|c|c|}
\hline \multirow[b]{2}{*}{ Variable } & \multicolumn{2}{|c|}{ Cases } & \multicolumn{2}{|c|}{ Controls } & \multirow[b]{2}{*}{$P$ value for $\chi^{2}$} \\
\hline & $n$ & $\%$ & $n$ & $\%$ & \\
\hline \multicolumn{6}{|l|}{ Gender } \\
\hline Male & 66 & $28 \cdot 21$ & 132 & $28 \cdot 21$ & Matched \\
\hline Female & 168 & $71 \cdot 79$ & 336 & $71 \cdot 79$ & \\
\hline \multicolumn{6}{|l|}{ Age (years) } \\
\hline$\leq 44$ & 12 & $5 \cdot 13$ & 22 & $4 \cdot 70$ & Matched \\
\hline $45-54$ & 21 & 8.97 & 44 & $9 \cdot 40$ & \\
\hline $55-64$ & 90 & $38 \cdot 46$ & 178 & 38.03 & \\
\hline$\geq 65$ & 111 & $47 \cdot 44$ & 224 & $47 \cdot 86$ & \\
\hline \multicolumn{6}{|l|}{ Education (years of education) } \\
\hline$\leq 10$ & 115 & $49 \cdot 15$ & 157 & $33 \cdot 55$ & \\
\hline $11-13$ & 70 & $29 \cdot 91$ & 192 & $41 \cdot 03$ & \\
\hline$\geq 14$ & 49 & $20 \cdot 94$ & 119 & $25 \cdot 43$ & $<0.0001$ \\
\hline \multicolumn{6}{|l|}{ Marital status } \\
\hline Married & 137 & $58 \cdot 55$ & 296 & $63 \cdot 25$ & \\
\hline Divorced/separated & 16 & $6 \cdot 84$ & 40 & 8.55 & \\
\hline Single & 13 & $5 \cdot 56$ & 25 & $5 \cdot 34$ & \\
\hline Widowed & 68 & $29 \cdot 06$ & 107 & $22 \cdot 86$ & NS \\
\hline \multicolumn{6}{|l|}{ Family history of diabetes } \\
\hline First-degree relatives without diabetes & 166 & $70 \cdot 94$ & 422 & $90 \cdot 17$ & \\
\hline First-degree relatives with diabetes & 68 & $29 \cdot 06$ & 46 & $9 \cdot 83$ & $<0.0001$ \\
\hline \multicolumn{6}{|l|}{$\operatorname{BMI}\left(\mathrm{kg} / \mathrm{m}^{2}\right)$} \\
\hline$\leq 24.9$ & 21 & 8.97 & 124 & $26 \cdot 50$ & \\
\hline $25 \cdot 0-29 \cdot 9$ & 57 & $24 \cdot 36$ & 185 & 39.53 & \\
\hline$\geq 30 \cdot 0$ & 156 & $66 \cdot 67$ & 159 & 33.97 & $<0.0001$ \\
\hline
\end{tabular}

Table 2 Odds ratios and $95 \%$ confidence intervals for type 2 diabetes mellitus in relation to egg consumption among cases ( $n$ 234) with a newly confirmed diagnosis of type 2 diabetes mellitus and age/gender-matched controls ( $n$ 468), Kaunas, Lithuania, 2001

\begin{tabular}{|c|c|c|c|c|c|c|c|c|c|c|}
\hline \multirow[b]{2}{*}{ Variable } & \multicolumn{2}{|c|}{ Cases } & \multicolumn{2}{|c|}{ Controls } & \multirow[b]{2}{*}{$\mathrm{OR}^{*}$} & \multirow[b]{2}{*}{$95 \% \mathrm{Cl}$} & \multirow[b]{2}{*}{$P$} & \multirow[b]{2}{*}{ ORt } & \multirow[b]{2}{*}{$95 \% \mathrm{Cl}$} & \multirow[b]{2}{*}{$P$} \\
\hline & $n$ & $\%$ & $n$ & $\%$ & & & & & & \\
\hline \multicolumn{11}{|l|}{ Egg consumption } \\
\hline$<1$ egg/week & 36 & $15 \cdot 38$ & 115 & $24 \cdot 57$ & $1 \cdot 00$ & - & & $1 \cdot 00$ & - & \\
\hline $1-1.9$ eggs/week & 78 & 33.33 & 161 & $34 \cdot 40$ & $1 \cdot 76$ & $1 \cdot 04,2 \cdot 98$ & & $1 \cdot 73$ & $1.00,3.00$ & \\
\hline 2-2.9 eggs/week & 64 & $27 \cdot 35$ & 114 & $24 \cdot 36$ & 1.97 & $1 \cdot 12,3 \cdot 46$ & & $1 \cdot 88$ & $1 \cdot 05,3 \cdot 34$ & \\
\hline 3-4.9 eggs/week & 40 & $17 \cdot 09$ & 60 & $12 \cdot 82$ & $2 \cdot 56$ & $1 \cdot 35,4 \cdot 85$ & & $2 \cdot 60$ & $1 \cdot 34,5 \cdot 08$ & \\
\hline \multirow[t]{2}{*}{$\geq 5$ eggs/week } & 16 & $6 \cdot 84$ & 18 & $3 \cdot 85$ & $3 \cdot 38$ & $1 \cdot 35,8 \cdot 49$ & & 3.02 & $1 \cdot 14,7 \cdot 98$ & \\
\hline & & & & & & & 0.001 & & & 0.003 \\
\hline
\end{tabular}

*OR adjusted for BMI, family history of diabetes, smoking and education level.

tOR adjusted for BMI, family history of diabetes, smoking, education level, morning exercise and plasma TAG level.

We found that consumers of $\geq 5$ eggs/week had three times greater risk of type 2 diabetes mellitus than those eating $<1$ egg/week. Prospective studies have shown similar results. Djoussé et $a l^{(14)}$ found that multivariable-adjusted hazard ratios for type 2 diabetes among individuals who consumed $\geq 7$ eggs/week were 1.58 in men and 1.77 in women, compared with no eggs consumed. In their study of 2849 Chinese adults (aged $\geq 20$ years), Shi et al. ${ }^{(15)}$ found that egg consumption was positively associated with the risk of diabetes. Participants who consumed $\geq 1 \mathrm{egg} / \mathrm{d}$ had $2 \cdot 28$ (95\% CI $1 \cdot 14,4.54)$ times greater risk of type 2 diabetes mellitus than those who consumed $<2$ eggs/week, and women who consumed $\geq 1 \mathrm{egg} / \mathrm{d}$ had three times greater risk ${ }^{(15)}$. Djoussé et al. ${ }^{(16)}$ studying 3898 older men and women from the Cardiovascular Health Study did not find the association between egg consumption or dietary cholesterol and increased risk of incident type 2 diabetes.
Salmeron et $a l .{ }^{(17)}$ found that total fat, SFA and MUFA intakes were not associated with risk of type 2 diabetes in women, but trans-fatty acids increased the risk and PUFA reduced the risk.

Eggs are a source of high-quality protein, with little total fat. Compared with other animal protein sources, eggs contain proportionately less saturated fat, which has generally been recognized as a strong dietary determinant of elevated LDL levels ${ }^{(18)}$. Epidemiological studies suggest that, among hyper-responders, dietary cholesterol from eggs leads to a modest increase in serum LDL cholesterol (LDL-C) and HDL cholesterol (HDL-C) concentrations and no effect on the ratio of LDL-C to HDL-C $\mathrm{C}^{(19-23)}$. It is estimated that each additional $100 \mathrm{mg}$ of dietary cholesterol intake results in an increase of $1.9 \mathrm{mg} / \mathrm{dl}$ in LDL-C and $0 \cdot 4 \mathrm{mg} / \mathrm{dl}$ in HDL-C ${ }^{(23)}$. Dietary cholesterol increases the susceptibility of LDL to oxidation, increases postprandial 
lipidaemia and potentiates the adverse effects of dietary saturated fat. Dietary cholesterol, including egg yolks, is harmful to the arteries ${ }^{(24)}$. Endothelial function refers to arterial vasomotor responses mediated predominantly by the release of nitric oxide (vasodilating) and endothelin (vasoconstricting) from the vascular endothelium, and plays an important role in the pathogenesis of atherosclerosis, hypertension, CVD and diabetes ${ }^{(25,26)}$.

Feskens and Kromhout ${ }^{(27)}$ studied 394 non-diabetic men (aged 50-70 years) in the Zutphen Study and found that saturated fat and dietary cholesterol intakes may affect glucose tolerance detrimentally. However, in their investigation of twenty-eight overweight or obese male patients (aged 40-70 years) on a carbohydrate-restricted diet, Mutungi et al. ${ }^{(28)}$ found that use of 3 eggs/d had no effects on fasting glucose compared with no egg consumption. On the other hand, Pearce et al. ${ }^{(29)}$ studied sixty-five participants with type 2 diabetes or impaired glucose tolerance and investigated the effect of a hypoenergetic high-protein/high-cholesterol diet $v$. a diet with a similar amount of animal protein (high-protein/ low-cholesterol) on plasma lipids, glycaemic control and cardiovascular risk markers. They found that the highprotein energy-restricted diet high in cholesterol from eggs improved glycaemic and lipid profiles, blood pressure and apo-B in individuals with type 2 diabetes ${ }^{(29)}$.

Djoussé and Gaziano ${ }^{(30)}$ from the Physicians' Health Study reported that egg consumption was positively related to total mortality in male physicians. This association was stronger among diabetic participants, who had a twofold increased risk of death $(2 \cdot 01 ; 95 \%$ CI $1 \cdot 26$, $3 \cdot 20)$ when comparing the highest with the lowest category of egg consumption $v$. non-diabetic participants.

Our work has some limitations that need to be acknowledged. First, egg consumption was self-reported by the participants and we cannot exclude reporting bias in the present study. The second limitation is that we did not calculate detailed nutrient and energy intakes from dietary habits.

\section{Conclusion}

Our data support a possible relationship of egg consumption and increased risk of type 2 diabetes mellitus.

\section{Acknowledgements}

This research received no specific grant from any funding agency in the public, commercial or not-for-profit sectors. No conflict of interest was declared. L.R. researched the data, contributed to the analysis, wrote the manuscript and edited the manuscript. R.O. researched the data, contributed to the analysis and edited the manuscript. The authors express sincere thanks to the staff of the Kaunas Dainavos Outpatient Clinic for providing affable conditions for the study.

\section{References}

1. Zimmet P, Alberti KG \& Shaw J (2001) Global and societal implications of the diabetes epidemic. Nature 414, 782-787.

2. Wild S, Roglic G, Green A et al. (2004) Global prevalence of diabetes. Estimates for the year 2000 and projections for 2030. Diabetes Care 27, 1047-1053.

3. Norkus A, Domarkienè S, Šulcaitè R et al. (2002) [Prevalence of carbohydrate disorders in Kaunas middle-age population]. Lietuvos endokrinologija 10, 60-66.

4. Naser KA, Gruber A \& Thomson GA (2006) The emerging pandemic of obesity and diabetes: are we doing enough to prevent a disaster? Int J Clin Pract 60, 1093-1097.

5. Song WO \& Kerver JM (2000) Nutritional contribution of eggs to American diets. J Am Coll Nutr 19, 5 Suppl., 556S-562S.

6. Hu FB, Manson JE \& Willett WC (2001) Types of dietary fat and risk of coronary heart disease: a critical review. $J \mathrm{Am}$ Coll Nutr 20, 5-19.

7. Herron KL \& Fernandez ML (2004) Are the current dietary guidelines regarding egg consumption appropriate? J Nutr 134, 187-190.

8. Lithuanian Department of Statistics (2009) Food Consumption. http://www.stat.gov.lt/lt/pages/view/?id=1241 (accessed November 2010).

9. Physicians Committee for Responsible Medicine (2008) Increased Egg Consumption Linked to Mortality. http://www. pcrm.org/health/veginfo/vegetarian_foods.html (accessed September 2010).

10. World Health Organization (1999) Definition, Diagnosis and Classification of Diabetes Mellitus and its Complications. Report of a WHO Consultation. Geneva: WHO.

11. World Health Organization (1995) Physical Status: The Use and Interpretation of Anthropometry. Report of a WHO Expert Committee. WHO Technical Report Series no. 854. Geneva: WHO.

12. Garrow JS \& Webster J (1985) Quetelet's index $\left(W / \mathrm{H}^{2}\right)$ as a measure of fatness. Int J Obes 9, 147-153.

13. Woodward M (1999) Case-control studies. In Epidemiology Study Design and Data Analysis, pp. 243-289. New York: Chapman, Hall/CRC.

14. Djoussé L, Gaziano JM, Buring JE et al. (2009) Egg consumption and risk of type 2 diabetes in men and women. Diabetes Care 32, 295-300.

15. Shi Z, Yuan B, Zhang C et al. (2011) Egg consumption and the risk of diabetes in adults, Jiangsu, China. Nutrition 27, 194-198.

16. Djoussé L, Kamineni A, Nelson TL et al. (2010) Egg consumption and risk of type 2 diabetes in older adults. Am J Clin Nutr 92, 422-427.

17. Salmeron J, Hu FB, Manson JE et al. (2001) Dietary fat intake and risk of type 2 diabetes in women. Am J Clin Nutr 73, 1019-1026.

18. Mente A, de Koning L, Shannon HS et al. (2009) A systematic review of the evidence supporting a causal link between dietary factors and coronary heart disease. Arch Intern Med 169, 659-669.

19. Weggemans RM, Zock PL \& Katan MB (2001) Dietary cholesterol from eggs increases the ratio of total cholesterol to high-density lipoprotein cholesterol in humans: a metaanalysis. Am J Clin Nutr 73, 885-891.

20. Knopp RH, Retzlaff BM, Walden CE et al. (1997) A doubleblind, randomized, controlled trial of the effects of two eggs per day in moderately hypercholesterolemic and combined hyperlipidemic subjects taught the NCEP step I diet. J Am Coll Nutr 16, 551-561.

21. Katz DL, Evans MA, Nawaz H et al. (2005) Egg consumption and endothelial function: a randomized controlled crossover trial. Int J Cardiol 99, 65-70.

22. Herron KL, Vega-Lopez S, Conde K et al. (2002) Premenopausal women, classified as hypo- or hyperresponders, 
do not alter their LDL/HDL ratio following a high dietary cholesterol challenge. J Am Coll Nutr 21, 250-258.

23. McNamara DJ (2000) The impact of egg limitations on coronary heart disease risk: do the numbers add up? J Am Coll Nutr 19, 5 Suppl., 540S-548S.

24. Spence JD, Jenkins DJ \& Davignon J (2010) Dietary cholesterol and egg yolks: not for patients at risk of vascular disease. Can J Cardiol 26, 336-339.

25. Vogel RA (2001) Measurement of endothelial function by brachial artery flow-mediated vasodilation. Am J Cardiol $\mathbf{8 8}, 31 \mathrm{E}-34 \mathrm{E}$.

26. Njike V, Faridi Z, Dutta S et al. (2010) Daily egg consumption in hyperlipidemic adults - effects on endothelial function and cardiovascular risk. Nutr J 9, 28.
27. Feskens EJ \& Kromhout D (1990) Habitual dietary intake and glucose tolerance in euglycaemic men: the Zutphen Study. Int J Epidemiol 19, 953-959.

28. Mutungi G, Ratliff J, Puglisi M et al. (2008) Dietary cholesterol from eggs increases plasma HDL cholesterol in overweight men consuming a carbohydrate-restricted diet. J Nutr 138, 272-276.

29. Pearce KL, Clifton PM \& Noakes M (2011) Egg consumption as part of an energy-restricted high-protein diet improves blood lipid and blood glucose profiles in individuals with type 2 diabetes. Br J Nutr 105, 584-592.

30. Djoussé L \& Gaziano JM (2008) Egg consumption in relation to cardiovascular disease and mortality: the Physicians' Health Study. Am J Clin Nutr 87, 964-969. 